\title{
Analysis of Power Marketing Data Mining Based on the Big Data Technology
}

\author{
Jiwen Yu, Xiaoxiao Shu, Chao Shang and Fan Liu \\ State Grid Jiangxi Electric Power Research Institute, Jiangxi Nanchang 330096
}

Keywords: Data mining; Decision support system; Database; DSS

\begin{abstract}
The essay Introduces about the key technology database, OLAP and data mining technology in the framework of marketing decision support system of power supply enterprises.As for themethod for the mining spaceselection in the data mining model, an artificial neural network structure and algorithm is used, which can not only avoid complicated nonlinear modeling problemin statistical methods but also have a smaller calculation amount than general nerve networkvariable selection method. It is in accordance with the actual situationof its power marketing that this paper designs the Database, OLAP scheme and the specific selection method ofdata mining space.It is hoped that the research results of this paper would have some reference valuefor designation and implementation of the scheme of power marketing decision support system under the market environment of power.
\end{abstract}

\section{Introduction}

The power industry has concentrated capital and technology, and this is its characteristic. Nowadays, the power industry is transforming from a complete monopolized company with integrated power generation, transmission and distribution under the planned economic system to the one with electricity marketization, which is purposed to introduce the competition system into the monopoly system of traditional power industry so as to heighten their efficiency, reduce the electricity supply cost and electricity prices, and to promote the national economic development. With the widespread use of a variety of management information systems (power marketing MIS, power MIS, scheduling MIS, etc.) in power enterprises, vast amounts of basic data comes out which presents in front of the operators and the decision makers a vast ocean of data instead of database of one department or the company, and this leads to a phenomenon of "data explosion but lack of knowledge".

In response to this situation, data mining technology for decision support comes into being. As the core technology of Knowledge Discovery in Database (KDD) and the products of a combination of artificial intelligence and database, the data mining technology uses some specialized algorithms toextract effective patterns from the databaseand has ability to find potential rules from a large number of data to extract useful knowledge. Data mining and knowledge discovery based on database, artificial intelligence and statistics has been widely used in fields of commercial, industrial and medical, and become one of the active research fields international and have shown its broad application prospects. Data mining technology is gradually integrated into the decision support system, so to solveproblem of knowledge acquisition "bottleneck" facing by the traditional decision support system and other problems in series, and becomes an important part of the decision-making system.

\section{Data Mining}

Data mining also known as dada exploit and data excavation is an advanced process of extracting model (knowledge) that is potential, effective and easy for understanding according to set business object by using methods based on computer (including new technologies).

Prediction and description are two basic goals of the data mining. Prediction means to predict unknown or future known values of other interested variable elements or numeric fields by using some existingvariable elements or numeric fields in database; description refers to find an 
understandablepattern for data description. According to the differences of knowing knowledge, the basic task of the data mining includes: correlation analysis, clustering, classification (concept description), deviation detection, and prediction.

It is generally composed of three phases: data preparation, data mining, and interpretation and evaluation, as shown in Fig. 1.

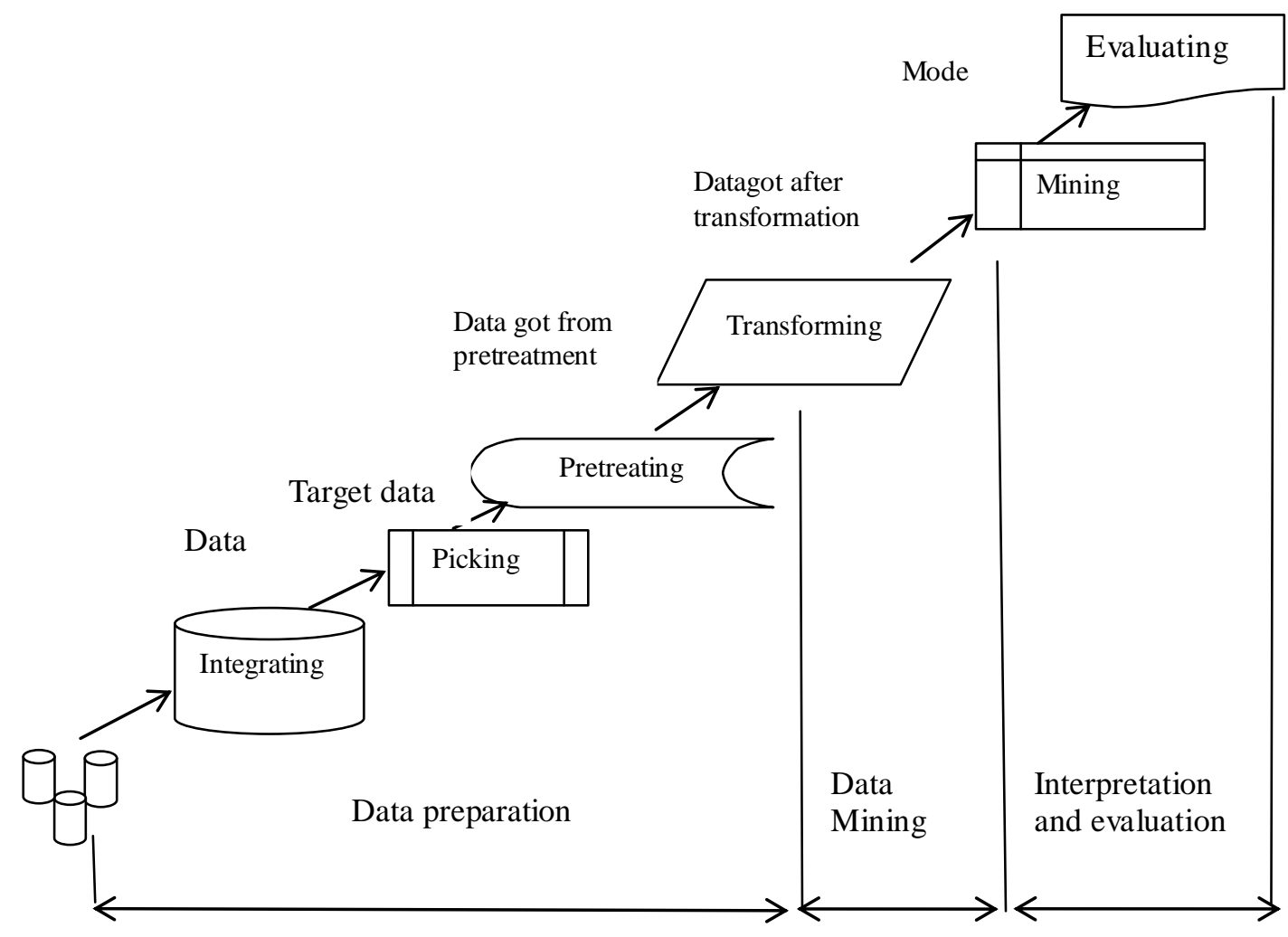

Figure 1. Data mining process

Data Preparation: The first stage of data mining.Its results will affect the efficiency of data mining, accuracy and the effectiveness of the final mining model.This phase can be subdivided into four steps: data integration, data selection, data preprocessing, and data conversion.

Data Mining: Select and apply appropriate data mining techniques to extract knowledge of interest from data that can be expressed in a specific way or expressed in some common ways.

Interpretation and evaluation: It is to analyze about the extracted knowledge in accordance with the end user's decision thus to distinguish the most valuable information for them. The knowledge in this process should not only be expressed in an understandable way but also be effectively evaluated. If it cannot meet the user's requirements, the upper process for data mining shall be repeated.

\section{Application Analysis of Data Mining DSS}

Power Marketing Decision Support System (PMDSS) is a wide ranged and complicated complex DSS. According to theactual situationanalyzed above and in connection with the problems of the traditional DSS system, a DSS system with new structure will be designed in this paper by using data mining technology to better meet the needs of practical applications. The structure and data flow of the PMDSS system which is logically divided into 6 phases can be seen in Fig. 2: 


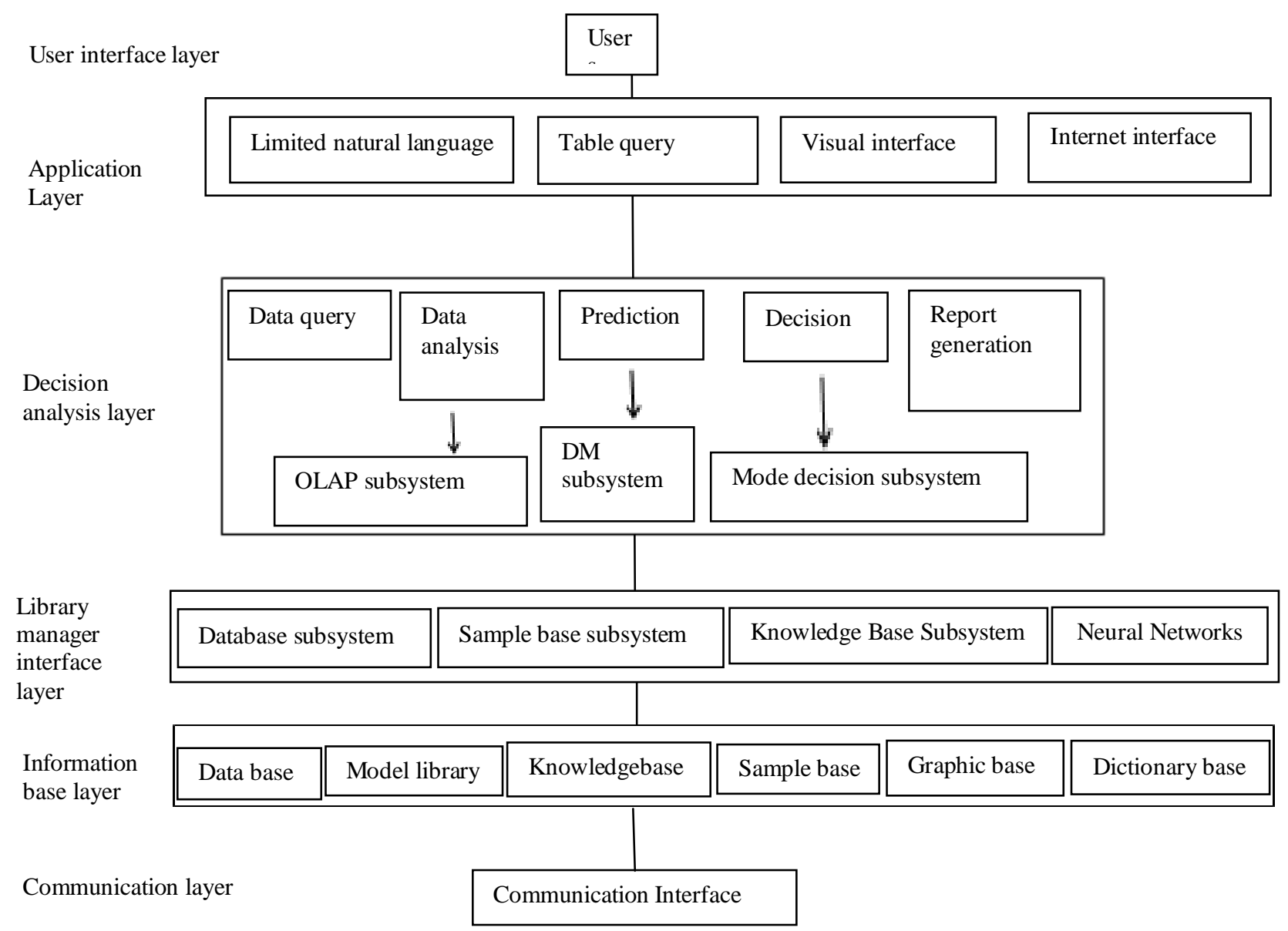

Figure 2. PMDSS system structure and data flow

User Interface Layer. A graphical user interface is included that provides information and communication between users and systems.

Application Layer. It includes the guidance, interpretation and control functions of specific five business functions, and is the probleminterface part for PMDSS system. In addition, the languagemodule is added to complete a natural language interpretation and processing functions for other related issues input by the users.

Decision Analysis Layer. It is the core of the PMDSS system, and is composed by OLAP subsystem, DM subsystem and model decision subsystem.OLAP can realize multi-dimensional analysis, DM explore the data hidden within the knowledge and laws, and model decision-making subsystemcan get solution through several of mathematical statistical decision-making model.

Library Management and Interface Layer. It completes interface functions of various types of data and management functions of the information base, including building, storage, update and maintenance of the library.

Information library layer. It is the direct operation source for the information knowledge and data storage of the entire system, including six library, in which the data warehouse is taken instead of traditional database, in addition, the decision-making programs and information is added for decision-making information base to store and retrieve about the history.

Communication Layer. Through this layer, the original data including internal grass-roots business data and the necessary external data can be accessed to the power marketing decision support system. 


\section{Analysis and Design of Power Marketing OLAP}

For different DSS systems, the methods and models used are different.The functional objectives of the power marketing decision-making system of the power supply company in one city are mainly based on the OLAP multidimensional analysis technology and supplemented by data mining and statistical forecasting models to achieve a comprehensive analysis. Below is to elaborate relevant issues from the view of analytic methods and contents.

Analysis of Changes of Electricity Sale and its Influencing Factors. The OLAPanalysis of electric power company involves statistics of the electricity consumption and its changes of users in each category, and the fact (measures)of the analysis includes: the sales volume, the last sales volume, year on year growth. Analysis of dimensions include: time (year), user category, industry, and region and so on. These are generally analyzed using OLAP technology.

Analysis of Changes of the Average Unit Price and its Influencing Factors. Analysis of changes of the average unit price is an important way to analyze changes in sales revenue from another perspective. The fact (measures)of the analysis includes:the average price of theelectricitysale, the last average price of last time electricity sale and the main impacting factors which are basic electricity increase or decrease, electricity tariff increase and decrease, price increase or decrease, power rate adjustment increase or decrease, and increase or decrease after the promotion.Analysis of dimensions include: time (year), user category, industry, and region and so on.All of these analyses can take use of OLAP technology and make analysis from following aspects: a. in which region the electricity sale income changes more and what is the main influencing factors; $b$. for user in important category, how to adjust its electricity price strategy to ensure an increase of sale income for the company.

Analysis of the Structure and the Reason for Owing Electricity Bill. Analysis ofowing electricity bill is one of the important contents of power marketing analysis. The fact (measures)of the analysis includes: the current electricity bill receivable, the current charged bill, the current owing bill, the current recovery rate of the bill, last owing bill and the last recovery rate of the owing bill. Analysis of dimensions include:time (Year), user category, industry category, and region and so on. The analysis of these contents is too mainly based on OLAP technology.

\section{Conclusion}

The power system reform in China has been deepened and perfected,and the power industry will gradually realize the independent operation of power generation, transmission and distribution, andthe existing power supply MIS consequently cannot meet the actual needs of power marketing, and so it is necessary to build more advanced power marketing decision support system that meets the needs of future analysis of decision-makingon the existing basis. In the basis of actual situation of power marketing in China, this paper makes a deep research on the structure of power marketing decision support system and several key technologies involved combing with data warehousing, OLAP and mining technology, and proposes a new structure framework of power marketing decision support system after a detailed demand analysis on powermarketing. The main feature of the system structure is to make integration of DW, OLAP and DM technology which can better meet the actual needs of power marketing decision support system.

\section{References}

[1] X Du, L Wang and A Sun, The development and application of GIS on power marketing and expansion[C]// The, International Conference on Information Science and Engineering. IEEE, 2010:4143-4146.

[2] Z Wang, Electric power marketing Ideology and tactics[J]. Heilongjiang Electric Power, 2003.

[3] H.E Weimin, Y Zou and L Wang, Research on electric power marketing service risk based on customer perspective[J]. Modern Electronics Technique, 2016. 
[4] Y Zhao, R.C Zhang, A power marketing data-mining system based on Web[J]. Journal of Henan Polytechnic University, 2010.

[5] J.X Long, T.M Wang, Implementation of business integrated platform for power marketing system[C]// The, IEEE International Conference on Information Management and Engineering. IEEE, 2010:460-465.

[6] X Du,The Development and Application of Geographical Information System on Power Marketing Business Expanding[J]. Electrical Engineering, 2010, 132(5):689-694.

[7] S.C Han, Y.L Zhang and L.Y Zhang, Benefit analysis of mobile inspection operation terminals in electric power marketing[J]. Power Demand Side Management, 2016.

[8] J Meng, Y Yang, The application of improved decision tree algorithm in the electric power marketing[J]. 2012:1-4.

[9] J Liu, C.J Hu, Research on the Power Marketing Technique Supporting System Based on Semantic Web Services[J]. 2011.

[10] A Zhao, Analysis on the Efficiency of Improving Meter Reading in Power Marketing[J]. Modern Industrial Economy \&Informationization, 2015.

[11] X.H Hao, J Zhu and W.Z Wang, et al. Application Status of Data Mining Technology in Power Marketing System[J]. Industry \& Mine Automation, 2011.

[12]X Zhang, Analysis of Power Marketing Risks and Countermeasures[J]. Electronic Test, 2015. 